\title{
Prevalence of rifampicin-resistant tuberculosis and its associated factors in a tertiary health care center, South-west Nigeria: A 5-year review
}

Abiodun Ronke Ojewuyi ( $\sim$ ojewuyia@gmail.com )

Bowen University Teaching Hospital https://orcid.org/0000-0002-3811-1967

Abiona Oluwadamilola Odeyemi

Bowen University Teaching Hospital https://orcid.org/0000-0002-1670-7321

Abimbola Ololade Odeyemi

Bowen University Teaching Hospital https://orcid.org/0000-0003-2934-8775

Amadin Aitua Olotu

Bowen University Teaching Hospital

Tunde Oladipo

Bowen University Teaching Hospital

\section{Research Article}

Keywords: Mycobacterium tuberculosis, Rifampicin resistance, MDR-TB, GeneXpert

Posted Date: March 8th, 2021

DOI: https://doi.org/10.21203/rs.3.rs-153296/v2

License: (9) This work is licensed under a Creative Commons Attribution 4.0 International License.

Read Full License 


\section{Abstract}

\section{Background}

Tuberculosis is a chronic disease with associated high morbidity and mortality. In recent decades, there has been an increase in resistance to drugs used in the treatment of tuberculosis. This is a major stumbling block in the global fight against tuberculosis. This study was to demonstrate the current prevalence of rifampicin-resistant tuberculosis and its associated predisposing factors in a Teaching Hospital in Nigeria.

\section{Methods}

This was a cross-sectional retrospective study involving 359 consecutive patients with bacteriologically confirmed tuberculosis seen between January 2015 and December 2019. Drug susceptibility testing was performed for rifampicin using GeneXpert MTB/RIF assay. Relevant information was obtained from the clinical records of the patients with the use of a well-structured proforma. The data obtained were analysed using the Statistical Package for Social Sciences (SPSS) version 23.0.

\section{Results}

There were a total of 359 patients out of which the majority, 235 (65.5\%) were males. The mean age was $39.78 \pm 16.31$ (range 1 - 90 years). A larger percentage of the subjects were new cases of tuberculosis $(n=312,86.9 \%), 49(13.6 \%)$ were HIV positive. The overall prevalence of rifampicin resistance found was $2.5 \%(n=9 / 359)$. There was a significant association between gender $(p=0.005)$ and re-treatment $(p=0.003)$. There was no significant association between rifampicin resistance and other factors including age and HIV.

\section{Conclusion}

Male gender and patients on re-treatment for tuberculosis are more at risk of developing resistance to rifampicin in our environment. There is a need to ensure compliance with all guidelines in the management of tuberculosis to prevent an increase in drug resistance.

\section{Introduction}

Tuberculosis (TB) is a chronic infectious disease caused by a group of acid-fast bacteria called the Mycobacterium tuberculosis complex (MTC). ${ }^{1}$ It has been decades since the tubercle bacillus was identified and described, and with a consensus agreement on the treatment guidelines. ${ }^{2}$ Despite the tremendous progress made in diagnosis and management of patients including the introduction of rapid diagnostic techniques such as GeneXpert MTB/RIF system, ${ }^{3}$ tuberculosis is still among the 10 highest causes of death, in the developing world and it is the leading cause of death from a single infectious agent. ${ }^{3}$ The persistent high rate in morbidity and mortality from tuberculosis is in part due to a higher 
incidence of drug-resistance Mycobacterium tuberculosis resulting in more expensive and difficult treatment options. ${ }^{2}$ Besides, some factors such as poverty, civil unrest or wars in some countries, Internally displaced persons (IDP) camps and recently the SARS-CoV-2 pandemic have all resulted in poor life quality. ${ }^{2}$ Also, poor housing systems, overcrowding, malnutrition and inability to access appropriate health care contributes greatly to an increase in disease burden and poorer outcomes. ${ }^{3}$

There were an estimated 10 million new cases of TB in 2019 and the Africa continent accounted for $25 \%$ of these cases, ${ }^{2}$ some eight countries accounted for two-thirds of the total cases globally: India (26\%), Indonesia (8.5\%), China (8.4\%), the Philippines (6.0\%), Pakistan (5.7\%), Nigeria (4.4\%), Bangladesh (3.6\%) and South Africa $(3.6 \%){ }^{2}$

Rifampicin resistance (RR-TB) is resistance to rifampicin (one of the first-line drugs used in the treatment of tuberculosis) detected using either phenotypic or genotypic methods, with or without resistance to the other anti-TB drugs. ${ }^{4}$ It includes any resistance to rifampicin whether mono-resistance, multidrug resistance (in addition to isoniazid), poly-drug resistance (resistance to more than one first-line anti-TB drug, involving either of isoniazid or rifampicin) or extensive drug resistance (resistance to any fluoroquinolone, and at least one of three second-line injectable drugs in addition to multidrug resistance) .4 Rifampicin resistance is accepted as a surrogate marker of multidrug-resistant tuberculosis and it often reveals the presence of greater than $90 \%$ of isoniazid resistance. ${ }^{5}$

Multidrug-resistant TB (MDR-TB) is defined as resistance to isoniazid and rifampicin. ${ }^{4}$ In the past few decades, there was a record of low prevalence of drug-resistant TB in Sub-Saharan Africa. ${ }^{6}$ However, recent studies have shown an increase in cases of drug-resistant TB on the continent. Some studies have reported a high prevalence of MDR-TB in patients from Nigeria ranging from $4 \%$ to $76.4 \%,{ }^{7-10}$, these studies were done at different times and regions in different categories of patients. However, the highest prevalences from these reports were in patients who were previously treated for tuberculosis.

Worldwide in 2019 , close to half a million people developed rifampicin-resistant TB (RR-TB), and $78 \%$ of these cases were multidrug-resistant TB. ${ }^{2}$ It was also found worldwide that a large number of the patients with MDR-TB were previously treated tuberculosis patient. The World Health Organization (WHO ) reported that globally in $2019,3.3 \%$ of new TB cases and $17.7 \%$ of previously treated cases were MDR/RR-TB cases. ${ }^{2}$ Transmission of Drug-resistant TB is both from person to person and emergence in a previously treated tuberculosis patient ${ }^{2}$ and this poses a great challenge in the global fight against tuberculosis.

Despite the success made so far in the control of TB, Nigeria remains one of the 30 high burden TB countries in the world. ${ }^{2}$ One of the factors negatively affecting the fight against TB is the on-going transmission of drug-resistant TB. ${ }^{2}$ It is imperative to carry out surveys to determine the prevalence of resistance to all commonly used drugs in the management of tuberculosis on regular basis, this will aid the development of policies in the management of patients with tuberculosis. 
This study aimed to determine retrospectively the prevalence of rifampicin resistance (RR-TB) and its associated factors in patients who attended the tuberculosis clinic and treatment centre at Bowen University Teaching Hospital (BUTH), Ogbomoso between January 2015 and December 2019.

\section{Methods And Materials}

\section{Study Design}

This was a retrospective cross-sectional study involving the review of the documented records and laboratory results of all patients with tuberculosis seen at the TB/DOTs clinic of BUTH, Ogbomoso. Drug susceptibility testing was performed for rifampicin using GeneXpert MTB/RIF assay. The study period covers from $1^{\text {st }}$ January 2015 to $31^{\text {st }}$ December 2019.

The study was carried out at the TB/DOTs clinic of BUTH Ogbomoso. This clinic is supported by the National Tuberculosis and Leprosy control programme. On account of its location within BUTH, the clinic serves the people residing within its locality, also people from across the town and neighbouring towns. Ogbomoso is located on latitude 8" $08^{\prime} 00^{\prime \prime}$ East and longitude of 4" $16^{\prime} 00^{\prime \prime}$ North of the Equator. It is the second-largest city in Oyo State, Nigeria after Ibadan the State capital.

The patients who had rifampicin resistance (RR-TB) were referred for treatment at the MDR-TB treatment centre University College Hospital, Ibadan but they report back to BUTH for follow up.

The data of patients of all age group and gender with microbiologically confirmed tuberculosis by GeneXpert MTB/RIF system assay were eligible and included in the study population. Patients who were managed for tuberculosis but did not have a GeneXpert MTB/RIF system report were excluded from the study.

Ethical approval for this study was obtained from the Research Ethics Committee of BUTH.

The data obtained were analysed using the Statistical Package for Social Sciences (SPSS) version 23.0 (SPSS Chicago Inc., IL, U.S.A). Continuous variables were expressed as means (standard deviation). The relationship between categorical variables was determined using Pearson chi-square. A p-value equal to or less than 0.05 was considered significant. Binary Logistic Regression was done to determine factors associated with rifampicin resistance.

\section{Results}

The clinic had a total of 524 TB cases during the five-year. Some patients were referred to other centres while some had their diagnosis made by clinical judgement. Only 359 of these patients including both new and re-treatment cases who had GeneXpert MTB/RIF system assay done were included in the study.

The majority of the patients, 235 (65.5\%) were males, the mean age was 39.78 \pm 16.31 (age range 1 - 90 years) (Table 1). A majority $(312,86.9 \%$ ) of these patients were newly diagnosed with tuberculosis (Table 
1), nine (2.5\%) of these had rifampicin-resistant tuberculosis. There was a significant association between male gender and rifampicin resistance, $p=0.005$ (Table 2). There was also a significant association between treatment category and rifampicin resistance, $p=0.003$ (Table 2), re-treatment for tuberculosis is a risk factor. No significant association was observed with age, HIV status, treatment outcome and RR-TB (Table 2). The odds of developing rifampicin resistance were significantly greater in those being re-treated for tuberculosis. Hence, treatment category is a determinant of rifampicin resistance (Table 3).

Table 1: Socio-demographic characteristics

\begin{tabular}{lll}
\hline Variables & $\begin{array}{l}\text { Frequency (n) } \\
\mathbf{n = 3 5 9}\end{array}$ & Percentage (\%) \\
\hline Age (in years) & 40 & 11.1 \\
$1-20$ & 173 & 48.2 \\
$21-40$ & 107 & 29.8 \\
$41-60$ & 37 & 10.3 \\
$61-80$ & 2 & 0.6 \\
$81-100$ & & \\
Gender & 235 & 65.5 \\
Male & 124 & 34.5 \\
Female & & \\
HIV status & 49 & 13.6 \\
Positive & 310 & 86.4 \\
Negative & & \\
Treatment category & 312 & 86.9 \\
New TB cases & 47 & 13.1 \\
Re-treatment cases & & \\
Re-treatment cases class (n=47) & 19 & 40.4 \\
Relapse & 17 & 36.2 \\
Treatment after failure & 7 & 14.9 \\
Treatment after loss to follow-up & 8.5 \\
Other previously treated & 4 & 14.2 \\
Outcome & & \\
Successful treatment & 308 & \\
Unsuccessful treatment & 51 & \\
\hline
\end{tabular}

Table 2: Relationship between rifampicin resistance and patient characteristics 


\begin{tabular}{|c|c|c|c|c|}
\hline \multirow[t]{2}{*}{ Variables } & \multicolumn{2}{|c|}{ Rifampicin resistance } & \multirow[t]{2}{*}{ Test statistics } & \multirow[t]{2}{*}{ P-value } \\
\hline & $\begin{array}{c}\text { Yes, n (\%) } \\
n=9\end{array}$ & $\begin{array}{c}\text { No, n (\%) } \\
n=350\end{array}$ & & \\
\hline \multicolumn{5}{|l|}{ Age } \\
\hline $1-20$ & $0(0.0)$ & $40(100.0)$ & $\mathrm{LR} \chi 2=2.919$ & 0.572 \\
\hline $21-40$ & $6(3.5)$ & $167(96.5)$ & & \\
\hline $41-60$ & $2(1.9)$ & $105(98.1)$ & & \\
\hline $61-80$ & $1(2.7)$ & 36 (97.3) & & \\
\hline $81-100$ & $0(0.0)$ & $2(100.0)$ & & \\
\hline \multicolumn{5}{|l|}{ Gender } \\
\hline Male & $9(3.8)$ & $226(96.2)$ & $\mathrm{LR} \chi 2=7.749$ & 0.005 \\
\hline Female & $0(0.0)$ & $124(100.0)$ & & \\
\hline \multicolumn{5}{|l|}{ HIV status } \\
\hline Positive & $2(4.1)$ & 47 (95.9) & $\chi^{2}=0.576$ & 0.448 \\
\hline Negative & $7(2.3)$ & $303(97.7)$ & & \\
\hline \multicolumn{5}{|l|}{ Treatment category } \\
\hline New & $4(1.3)$ & $308(98.7)$ & Fisher's Exact Test & 0.003 \\
\hline Re-treatment & $5(10.6)$ & $42(89.4)$ & & \\
\hline Outcome & & & $\chi 2=0.073$ & \\
\hline Successful treatment & $8(2.6)$ & $300(97.4)$ & & 0.788 \\
\hline Unsuccessful treatment & $1(2.0)$ & $50(98.0)$ & & \\
\hline
\end{tabular}

Table 3: Binary Logistic Regression of factors associated with rifampicin resistance Independent variables Dependent variable $=$ Rifampicin resistance

\begin{tabular}{llll} 
& Odds ratio & $\mathbf{9 5 \%}$ CI & p-value \\
\hline Gender & 0.0 & 0.000 & 0.995 \\
Treatment category & $\mathbf{1 1 . 5 5 8}$ & $\mathbf{2 . 9 1 9 - \mathbf { 4 5 . 7 6 4 }}$ & $\mathbf{0 . 0 0 0 *}$ \\
\hline
\end{tabular}

*Significant.

\section{Discussion}

The prevalence of rifampicin-resistant tuberculosis (RR-TB) in patients who had GeneXpert MTB/RIF system assay done at our centre over the period of review was $2.5 \%(n=9 / 359)$. Resistance to rifampicin was significantly associated with gender $(p=0.005)$ and treatment category $(p=0.003)$, with male patients and patients on re-treatment being more at risk of infection with rifampicin-resistant tuberculosis. This establishes further the need to ensure compliance with the standard guidelines when managing patients 
with tuberculosis, especially when they are males. This will prevent the development of resistance to the first-line drugs used in treatment.

A similar study in Nasarawa, ${ }^{11}$ Delta, ${ }^{12}$ and Benue, ${ }^{13}$ states in Nigeria, reported a higher prevalence of $6 \%$, $7.3 \%$ and $13.9 \%$ RR-TB respectively in patients with tuberculosis. The disparity in the prevalence found could be due to different patient groups, socioeconomic class, sampling methods, the period of sampling and regional variations in tuberculosis prevalence. In addition is the higher prevalence of Internally displaced persons (IDP) camps in the aforementioned states compared to where this study was carried out.

MDR-TB/RR-TB is found more in patients on re-treatment, ${ }^{2}$ and in this study, there was a significant association between TB re-treatment and RR-TB $(p=0.001)$. Treatment category was found to be a determinant of RR-TB by binary logistic regression. Five (55.6\%) of the 9 patients with RR-TB were patients on re-treatment, this is similar to reports from other states reporting a higher prevalence of RR-TB in patients on re-treatment. ${ }^{13,14}$. From previous studies, it has been established that acquired resistance to anti-tuberculous drugs is usually from previous exposure to drugs used in the treatment of tuberculosis, poor compliance with drug regimen and also a breach in the laid down protocols. ${ }^{15,16,17}$ This could explain the higher prevalence of RR-TB found in patients on re-treatment. It is imperative to ensure strict compliance with the laid down protocols in the treatment of TB, this is to prevent the development of resistance to drugs used as first-line in the management of the disease.

We found a significant association between male gender and RR-TB $(p=0.003)$, all nine patients $(100 \%)$ who had rifampicin-resistant TB were males. However, gender was not found to be a determinant of RRTB by logistic regression. Some reports from the Southwest and Southeastern part of Nigeria also did not find a significant association between gender and MDR-TB. ${ }^{10,18}$ But, a study done in Delta state, Nigeria reported the male gender as one of the independent variables in the development of RR-TB. ${ }^{12}$ WHO have also reported TB to be commoner in the male gender, and they are at risk of dying from the disease more than women. ${ }^{19}$ Several factors could be responsible for this including MDR-TB.

There was no significant association between age group and RR-TB in this study. But, a larger percentage $66.7 \%(n=6)$ of the patient with RR-TB were within the age group 21-40 years, a similar report from Benue state in Nigeria and Ethiopia reported 30 years as the mean age for presentation with RR-TB. ${ }^{13,15}$ There was also no significant association between HIV status and infection with RR-TB and this is similar to the report from Delta state in Nigeria, which also found no association between HIV status and RR-TB. ${ }^{12}$ However, the study done in Nasarawa state with a high prevalence of HIV infection found an association between HIV and RR-TB. ${ }^{11}$ This disparity could be due to the higher prevalence of HIV infection and subsequent higher prevalence of tuberculosis infection in Nasarawa state. ${ }^{11}$ Thus, a positive HIV status does not necessarily influence the development of RR-TB in patients.

The majority $(88.9 \%, n=8)$ of the subjects involved in this study were cured, having completed treatment as recommended by the national policy without evidence of failure and with three or more consecutive 
sputum samples taken at least 30 days apart remaining negative after the intensive phase as recognized by $\mathrm{WHO}^{4}$

\section{Conclusion}

Our study found a low prevalence of RR-TB in our community with male gender and re-treatment for tuberculosis as risk factors for the development of rifampicin resistance. There is a need to increase awareness on the threat posed by drug-resistant tuberculosis and encourage more compliance with laid down guidelines in the management of tuberculosis. More efforts should also be put in place to ensure accurate diagnosis and prompt treatment of all patients with tuberculosis.

\section{LIMITATIONS}

1. There was sparse data on occupation/income, housing structure, and history of interaction with confirmed cases of TB/RR-TB. These factors could also have been considered in the assessment of risk factors.

2. There was no culture report for rifampicin resistance nor other drugs used in the treatment of tuberculosis which could have contributed to the outcome of the study.

\section{List Of Abbreviations}

TB - Tuberculosis

MTC - Mycobacterium tuberculosis complex

SARS-CoV-2- Severe acute respiratory syndrome coronavirus 2

RR-TB - Rifampicin resistant tuberculosis

MDR-TB - Multidrug resistant tuberculosis

DOTS- Directly Observed Treatment, short-course

BUTH - Bowen University Teaching Hospital

SPSS - Statistical Package for Social Sciences

HIV - Human Immunodeficiency Virus

WHO - World Health Organization

IDP- Internally displaced persons

\section{Declarations}




\section{ACKNOWLEDGMENTS}

The authors acknowledge with gratitude the staff and patients of Bowen University Teaching Hospital, Ogbomoso. We appreciate the effort of the staff at the BUTH DOTs treatment centre and Tuberculosis Clinic.

\section{Competing Interests}

The authors declare that they have no competing interests.

\section{Authors' Contributions}

$\mathrm{AR}, \mathrm{AO}$ and $\mathrm{AO}$ were involved in data collection, processing, analysis, Interpretation of data and major contributors in writing the manuscript. TS analysed the samples and interpreted data. AA also contributed in writing the manuscript.

\section{Funding Information}

The funding for this work was sorely by the authors.

\section{Data Availability Statement}

The datasets used and/or analysed during the study are available from the corresponding author on reasonable request.

\section{Disclaimer}

The views expressed in this article are those of the authors and not an official position of the institution.

\section{References}

1. Daniel FW, Timothy SR, David HW. Mycobacterium tuberculosis. In: Mandell GL, Bennet JE, Dolin R (eds). Mandell, Douglas, and Bennett's Principle and Practice of Infectious Diseases.7Ed.Churchill Livingstone Elsevier. United States 2009; 3129.

2. World Health Organisation. Global tuberculosis report 2020. Geneva: World Health Organization; 2020. Licence: CC BY-NC-SA 3.0 IGO. Available from: https://www.who.int/publications/i/item/9789240013131[Accessed 5th November 2020].

3. World Health Organisation. Global tuberculosis report 2019. Geneva: World Health Organization; 2019. Licence: CC BY-NC-SA 3.0 IGO. Available from: https://www.who.int/teams/globaltuberculosis-programme/tb-reports/global-report-2019 [Accessed 21st November 2020].

4. World Health Organisation. Definitions and reporting framework for tuberculosis. Geneva: World Health Organisation; 2013. Available from: https://www.who.int/tb/publications/definitions/en/ [Accessed 27th December, 2020]. 
5. Jaleta KN, Gizachew M, Gelaw B, Tesfa H, Getaneh A, Biadgo B. Rifampicin-resistant Mycobacterium tuberculosis among tuberculosis-presumptive cases at University of Gondar hospital, Northwest Ethiopia. Infect. Drug Resist. 10, 185-192.

6. Musa BM, Adamu AL, Galadanci NA, Zubayr B, Chisom NO, Muktar HA. Trends in prevalence of multidrug resistant tuberculosis in sub-Saharan Africa: A systematic review and meta-analysis. PLoS One. 2017:12(9).doi 10.1371/journal.pone.0185105

7. Areeshi MY, Bisht SC, Mandal RK, Haque S. Prevalence of drug resistance in clinical isolates of tuberculosis from GCC: A literature review from January 2002 to March 2013. J. Infect. Dev. Ctries.2014;8(9). doi: 10.3855/jidc.4053.

8. Lawson L, Habib AG, Okobi MI, Idiong D, Olajide I, Emenyonu N, et al. Pilot study on multidrug resistant tuberculosis in Nigeria. Ann Afr Med. 2010 Jul-Sep;9(3):184-7. doi: 10.4103/15963519.68355. PMID: 20710112.

9. Ikuabe PO, Ebuenyi ID. Prevalence of rifampicin resistance by automated Genexpert rifampicin assay in patients with pulmonary tuberculosis in Yenagoa, Nigeria. Pan Afr. Med. J. 2018: 29, 204.

10. Olusoji D, Eltayeb O. Prevalence and risk factors associated with drug resistant TB in South West, Nigeria. Asian Pac. J. Trop. Med. 4, 148-151.

11. Egbe K, Ike AC, Aleruchi C. Prevalence of Tuberculosis and Rifampicin Resistance Among Patients Seeking Medical Care in Nasarawa State, North Central Nigeria. Science Journal of Public Health.2016; 4(3)214-218.

12. Ukwamedua H, Omote V, Etaghene J, Oseji ME, Agwai IC, Agbroko H. Rifampicin resistance among notified pulmonary tuberculosis (PTB) cases in South-Southern Nigeria. Heliyon. 2019 Jul 16;5(7):e02096. doi: 10.1016/j.heliyon.2019.e02096. PMID: 31360790; PMCID: PMC6639537.

13. Nwadioha SI, Nwokedi EO, Ezema GC, Eronini NC, Anikwe A, Audu F, et al. Drug Resistant Mycobacterium tuberculosis in Benue, Nigeria. MRJI 22May2014 4(9). [Internet]. [cited 8 January 2021]

14. Onyedum CC, Alobu I, Ukwaja KN. Prevalence of drug-resistant tuberculosis in Nigeria: A systematic review and meta-analysis. PLoS One. 2017: 12(7): e0180996.

https://doi.org/10.1371/journal.pone.0180996.

15. Mekonnen F, Tessema B, Moges F, Gelaw A, Eshetie S, Kumera G. Multidrug resistant tuberculosis: prevalence and risk factors in districts of Metema and West Armachiho, Northwest Ethiopia. BMC Infect Dis. 2015;15, 461. https://doi.org/10.1186/s12879-015-1202-7

16. Dheda K, Gumbo T, Maartens G, Dooley KE, McNerney R, Murray M. et al. The epidemiology, pathogenesis, transmission, diagnosis, and management of multidrug-resistant, extensively drugresistant, and incurable tuberculosis. Lancet Respir Med (2017) doi:10.1016/S2213-2600(17)300796. Epub ahead of print. PMID: 28344011.

17. Asgedom SW, Teweldemedhin M, Gebreyesus H. Prevalence of Multidrug-Resistant Tuberculosis and Associated Factors in Ethiopia: A Systematic Review", Journal of Pathogens, 2018, Article ID 7104921, 8 pages, https://doi.org/10.1155/2018/7104921 
18. Otu A, Umoh V, Habib A, Ameh S, Lawson L, Ansa V. Drug Resistance among Pulmonary Tuberculosis Patients in Calabar, Nigeria. Pulm Med. 2013;2013:235190. doi: 10.1155/2013/235190. PMID: 24078872; PMCID: PMC3781831.

19. World Health Organization. Tuberculosis and gender. Available from: https://www.who.int/tb/areasof-work/population-groups/gender/en/ [Accessed 26th December 2020]. 